Estuarine, Coastal and Shelf Science

Vol. 70, Issues 1-2, October 2006, Pages 259-270

http://dx.doi.org/10.1016/j.ecss.2006.04.020

(c) 2006 Elsevier Ltd All rights reserved
Archimer, archive institutionnelle de l'Ifremer http://www.ifremer.fr/docelec/

\title{
Diet overlap between harbour porpoise and bottlenose dolphin: An argument in favour of interference competition for food?
}

\author{
Jérôme Spitz ${ }^{a, b, ~}{ }^{*}$, Yann Rousseau ${ }^{a}$ and Vincent Ridoux ${ }^{a, c}$
}

\begin{abstract}
${ }^{a}$ Centre de Recherche sur les Mammifères Marins, Institut du Littoral et de l'Environnement, Université de La Rochelle, Avenue du Lazaret, 17000 La Rochelle, France

${ }^{\mathrm{b}}$ Ecole Pratique des Hautes Etudes, Laboratoire de Biogéographie et Ecologie des Vertébrés, Place Eugène Bataillon, 34060 Montpellier, France

${ }^{\circ}$ Centre de Recherche sur les Ecosystèmes Littoraux Anthropisés, UMR 6217,CNRS-Ifremer-

Université de La Rochelle, Avenue Michel Crépeau, 17042 La Rochelle, France

*: Corresponding author : Email : jspitz@univ-Ir.fr
\end{abstract}

\begin{abstract}
In aquatic ecosystems, competitive interactions are occasionally described. Violent attacks on harbour porpoises by bottlenose dolphins were reported and it was proposed that this behavior could result from competitive interactions for food. This hypothesis implies that the two predators should share all or part of they prey range. In this work, we describe the diets of each predator in the Bay of Biscay and adjacent areas from stomach content analysis of stranded animals. The diet of the harbour porpoise was mostly composed of small schooling fish living close to the seafloor (98 percent by mass). The diet of the bottlenose dolphin was characterised by the presence of large specimens of demersal fish (91 percent by mass) and cephalopods. Several prey species are common in the two diets and even the length distributions of some of them, such as sardine or scads, are very similar. However, global indices such as the Mantel test or the Pianka's index indicate no or weak overlap. The dietary results suggest that the two predators show partial dietary overlap over several major dimensions of the foraging niche: prey profile, foraging habitats, prey species and size range. We suggest interference competition is plausible at the scale of a prey school that would be exploited jointly by groups of the two predators.
\end{abstract}

Keywords: interference competition; top predator; diet; Phocoena phocoena; Tursiops truncatus; North-Eastern Atlantic 


\section{Introduction}

An accepted definition of the concept of competition is given by Keddy (1989) as "the negative effects which one organism has upon another by consuming, or controlling access to, a resource that is limited in availability". Then, most ecologists distinguish two forms of competition : exploitative competition when the competitive species are not in direct interaction but the consumption of food by one of them reduces resource availability to the others, and, the interference competition when direct conflicts break out between competitors (e.g. Keddy, 1989; Sih, 1993).

The observed diet of a marine predator is the combination of resource availability and foraging strategies. The former is determined by a combination of spatially-defined characteristics of the environment such as depth and slope, and more mobile or temporary features such as a wide variety of meso- to small-scale hydrological processes. The latter is determined by costs and benefits associated to foraging, linked to limitations in physiological, physical or social functioning. Thus, if several predators develop the same foraging technique and so, exploit the same resource, they are in a context where competition could occur. In top predators, exemplified by terrestrial carnivores (Caro and Stoner, 2003), competition can take different forms: avoidance, exploitative competition, food stealing or competitor killing. Aggressive interactions were largely documented for terrestrial predators; Palamores and Caro (1999) reviewed 97 pairs of African terrestrial carnivores shown to exhibit lethal aggressive competition.

In aquatic ecosystems, aggressive interactions are occasionally described. For marine mammals, predation by killer whales, Orcinus orca, on other marine mammals is largely documented (Jefferson et al., 1991), some social interactions are observed, specially, with delphinids (e.g. Herzing et al., 2003; Psarakos et al., 2003) and few anecdotic observations like infanticide were reported (Baird, 1998, Orr and Harwood, 1998, Patterson et al., 1998). Finally, violent interactions between bottlenose dolphins, Tursiops truncatus, and harbour porpoises, Phocoena phocoena, were reported, notably in British waters where they are estimated to be the first source of porpoise mortality in areas were both species occur (Ross and Wilson, 1996; Jepson and Baker, 1998; Santos et al., 2004). It was proposed that these attacks could notably result from competitive interactions for food (Ross and Wilson, 1996). The Bay of Biscay and the adjacent Northeast Atlantic Ocean are home to an abundant and diversified cetacean fauna, including the harbour porpoise and the bottlenose dolphin (Hammond et al., 2002; CRMM/ULR, unpublished data from sighting surveys in the Bay of Biscay). The two species' ranges partly overlap in coastal and shelf waters, although the bottlenose dolphin also extensively dwells further offshore. Direct and stranding evidences (C. Vincent, unpublished field observation; O. Van Canneyt, unpublished stranding data) suggest that, similarly to what is frequently observed in Scotland, attacks of harbour porpoises by bottlenose dolphins also occur.

In this work, we describe the diets of each predators from stomach content analysis of stranded animals and examine if these species do share similar prey preference in the aim of highlighting the potential for interference competition between the two species.

\section{Materials and methods}

\subsection{Collection of samples}

In this study, 29 stomachs of harbour porpoise and 25 of bottlenose dolphin stranded along the Northeast Atlantic French coast, Bay of Biscay and western Channel, were collected (Fig. 1). These animals were recovered and examined by members of the French stranding scheme from June 1988 to April 2003. The sample set includes individuals of both sexes, with immatures and adults. After necropsy, the stomachs were ligatured and stored deep-frozen $\left(-20^{\circ} \mathrm{C}\right)$ in polythene bags until further analyses.

\subsection{Sample analysis}

Sample analysis was aimed at describing the diet in terms of prey occurrence, relative abundance, calculated mass and size distribution and followed a general procedure which is now standard for marine top predators (Pierce and Boyle, 1991; Croxall, 1993; Ridoux, 1994). Each stomach was weighed, emptied in a tray and its wall weighed again to obtain the mass of the stomach content by difference. The stomach content was washed through a $0.2 \mathrm{~mm}$ mesh sieve. The diagnostic parts were recovered and stored dry for fish bones and otoliths or in $70 \%$ ethanol for cephalopod beaks, crustacean remains as well as any remain with flesh attached. The items found were identified to the lowest taxonomic level by using published guides (Lagardère, 1971; Clarke, 1986; Härkönen, 1986) and our reference collection of specimens caught by commercial or scientific trawlers in the Bay of Biscay and adjacent Atlantic areas. The total number of food items was estimated as the highest number given either by paired structures (otoliths, operculum, hyomandibular, dentary and premaxillary for fishes, upper and lower beaks for cephalopods and eyes for crustaceans) or impaired structures (parasphenoid for fishes, gladii for cephalopods and carapace and telson for crustaceans). Diagnostic hard parts such as beaks, otoliths and carapaces were measured by using a 
digital vernier calliper ( $\pm 0.02 \mathrm{~mm}$ ) following standards (Clarke, 1986; Härkönen, 1986). A random subsample of up to 30 diagnostic hard parts per prey species per stomach sample was measured.

\subsection{Dietary data analysis}

The occurrence of a given prey taxon is the number of stomachs in which this taxon was observed. The relative abundance is given by the number of individuals of the same taxon found throughout the sample set. The calculated biomass is given by the product of the average calculated body mass and the number of individuals of the same taxon in each sample, summed throughout the sample set. These three indices can be expressed by their percentage frequency with, respectively, percentage of occurrence $(\% \mathrm{O})$, percentage by number $(\% \mathrm{~N})$ and percentage by biomass $(\% \mathrm{M})$ :

$$
\% \mathrm{O}_{i}=\mathrm{n}_{i} / \mathrm{N} * 100
$$

where $\mathrm{n}_{i}$ is the number of stomachs where the prey $i$ was found and $\mathrm{N}$ the total number of stomachs ;

$$
\% \mathrm{~N}_{i}=\mathrm{x}_{i} / \mathrm{X} * 100
$$

where $\mathrm{x}_{i}$ is the number of prey $i$ found and $\mathrm{X}$ the total number prey ;

$$
\% \mathrm{M}_{i}=\left(\sum_{j} \mathrm{x}_{i, j} * \overline{\mathrm{Y}}_{i, j} / \sum_{i} \sum_{j} \mathrm{x}_{i, j} * \overline{\mathrm{Y}}_{i, j}\right) * 100
$$

where $x_{i, j}$ is the number of prey $i$ found in the sample $j$ and $\bar{Y}_{i, j}$ the average individual body mass of prey $i$ in sample $j$.

Individual prey body length and body mass were back-calculated by using relationships that either came from the literature (Clarke, 1986; Härkönen, 1986) or were fitted from measurements performed on specimens of our reference collection. Body size distribution was established on the basis of the whole series of individuals of each prey $i$. Therefore, size distributions were established at sample $j$ level from the 30 measured individuals or prey $i$, level-headed to total number of prey $i$ individuals in sample $j$ and summed throughout the sample series. These prey size distributions were constructed both as the percentage by number and the percentage by mass contributed by each size class, since these two variables convey quite different information about the importance to the diet of prey of varying body lengths.

Thus, the diets of these cetaceans were described by the following indices: occurrence, number and reconstructed mass as well as body size distributions for each prey species. $75 \%$ percentile for the compositions by number and by mass were generated by non-parametric bootstrap simulations allowing sampling error to be estimated (Reynolds and Aebischer, 1991). The bootstrapping routine was written by using the $R$ software (Ihaka and Gentleman, 1996). Random samples were drawn with replacement and the procedure was repeated 300 times. Possible biases related to subsampling for length measurements and to erosion of diagnostic parts were not estimated.

\subsection{Comparison of diets}

Firstly, some descriptive index were calculated to estimate and compare the characteristics of dietary niches. The specific richness (R) is the number of species found in the diet of a given predator. The common specific richness (Rc) is the number of species found in the diets of both predators. The biodiversity of prey was calculated by the Shannon-Wiener index $\left(\mathrm{H}^{\prime}\right)$ which considers both the specific richness and the number of specimens for each species.

$$
\mathrm{H}^{\prime}=-\sum p_{i} \log _{2} p_{i}
$$

where $p_{i}$ is the percentage by number of the prey $i$ founded in the diet.

The equitability gives the balance between the percentage by number of each prey. It varies from 0 to $1 ; 1$ indicating that each prey has the same percentage by number.

$$
\mathrm{E}=\mathrm{H}^{\prime} / \log _{2} \mathrm{R}
$$


The dietary overlap in number or in mass is obtained by the Pianka index (respectively $\mathrm{O}_{\mathrm{n}}$ et $\mathrm{O}_{\mathrm{m}}$ ). It varies from 0 (no overlap) to 1 (complete overlap).

$$
\mathrm{O}=\frac{\sum p_{i A} p_{i B}}{\sqrt{\sum p_{i A}^{2} \sum p_{i B}^{2}}}
$$

where $p_{i A}$ is the percentage by number (or mass) of the prey $i$ founded in the diet of predator $\mathrm{A}$ and $p_{i B}$ is the percentage by number (or mass) of the prey $i$ founded in the diet of predator $\mathrm{B}$.

The dispersion of our samples was examined by performing Correspondence Analyses (CAs). CA routines were done by using the software XLSTAT ${ }^{\mathcal{O}}$ v5.1 (Addinsoft). CAs allowed the homogeneity of the samples and the existence of sub-groups to be highlighted. The matrix was constituted by 0 (absence of prey species) or 1 (presence of prey species). According to Patterson (1986), the difference in prey taxa utilisation was estimated by using a Mantel test, a nonparametric statistical test for comparing two distance matrices. The first matrix consists of 0 and 1 depending on whether the species are the same or not ; the second one contains overlap values (Pianka's index) based on prey taxa. This correlation test was generated by the software XLSTAT $^{\mathcal{O}}$ v5.1 (10000 randomisations).

To compare differences in prey length distributions, the univariate Mann-Whitney test was used because of non-normal data.

\section{Results}

\subsection{Diet of harbour porpoise}

\subsubsection{General}

The total mass of examined food material was 5300g, i.e. an average stomach content mass of $182 \pm 227 \mathrm{~g}$ $(\mathrm{N}=29$; range 6 - 839). Identifiable material was retrieved from 26 out of 29 stomachs.

A total of 1728 prey individuals were found. They accounted for a total reconstructed biomass of $24072 \mathrm{~g}$. Fish, cephalopods and crustaceans were identified and represented a species richness of 19 (respectively 13,5 and 1 species). The average prey diversity was $3.4 \pm 2.2$ species per sample $(\mathrm{N}=26$ non empty stomachs). Fish dominated the diet (Table 1) both by number (85 \%) and mass (98\%). Crustaceans, represented by only one species, northern krill, Meganyctiphanes norvegica, reached $13 \%$ in relative abundance but were negligible in reconstructed mass. Cephalopods accounted for a low fraction of the diet either by number or by mass.

\subsubsection{Specific composition}

The diet of harbour porpoise along the Northeast Atlantic French coast was composed of a combination of groundfish (e.g. Gadidae, Atherinidae, Merluccidae) and some pelagic fish (e.g. Clupeidae, Carangidae, Scombridae). In terms of species importance, 6 fish species held more than $80 \%$ by number and $95 \%$ by mass (Table 1). Blue whiting, Micromesistius poutassou, was the most frequent prey with $39 \%$ of occurrence and it amounted to 19 and $21 \%$ in relative abundance and mass, respectively. Despite their lower relative abundance, sardine, Sardina pilchardus, scads, Trachurus trachurus (or/and $T$. mediterraneus) and whiting, Merlangius merlangus, represented the remainder of reconstructed biomass with 21, 28 and $20 \%$ respectively, as a result of their comparatively larger body size (Fig. 2). By contrast, gobies represented $22 \%$ by number but, owing to their very small body size (44 $\pm 11 \mathrm{~mm}$ body length), only $1 \%$ by mass. Similarly, northern krill $(29 \pm 0 \mathrm{~mm})$ accounted for $13 \%$ by number and only $0.2 \%$ by mass.

\subsubsection{Prey sizes}

The overall prey size distribution ranged from 8 to $307 \mathrm{~mm}$ with the mean at $130 \mathrm{~mm}$ (Fig. 3). Overall, 77 $\%$ of all prey individuals (mainly Trisopterus spp, gobidae, Meganyctyphanes norvegica) were smaller than $100 \mathrm{~mm}$ and only $9 \%$ (mainly Sardina pilchardus, Merlangius merlangus, Trachurus spp) were larger than $190 \mathrm{~mm}$ body length. Contrastingly, prey individuals smaller than $100 \mathrm{~mm}$ represented only $7 \%$ of the reconstructed biomass, whereas those over $190 \mathrm{~mm}$ accounted for $70 \%$ by mass.

\subsection{Diet of bottlenose dolphin}

\subsubsection{General}

The total mass of food remains was $27200 \mathrm{~g}$, i.e. an average of $1300 \pm 1229 \mathrm{~g}$ per sample ( $\mathrm{N}=25$; range 60 - 4398) and identifiable material was found in 21 out of 25 samples. A total of 1060 prey individuals were found, which accounted for a total reconstructed biomass of $174875 \mathrm{~g}$, with a species richness of 33 (25 
fish species, 3 cephalopods and 1 crustaceans). The diet was mostly composed of fish, with limited amounts of cephalopods and crustaceans as well. The average prey diversity was $4.7 \pm 2.1$ species per sample ( $\mathrm{N}=21$ non empty stomachs). Fish largely dominated (Table 2) by both number (94\%) and mass (91\%). Cephalopods represented $9 \%$ reconstructed mass and crustaceans accounted for a very low fraction of the diet either by number or mass.

\subsubsection{Specific composition}

The diet of bottlenose dolphin along the Atlantic French coast was composed of a combination of large groundfish and squid (e.g. Merluccidae, Mugilidae, Sparidae, Gadidae, Loliginidae) and some pelagic fish (e.g. Carangidae, Moronidae, Clupeidae) (Table 2). Hake, Merluccius merluccius, was the most important prey in this diet with $20 \%$ by number and $41 \%$ by mass. Scads and mullets, family Mugilidae, represented $13 \%$ and $12 \%$ by reconstructed biomass and $15 \%$ and $5 \%$ by number respectively. All these three species were represented by large specimens (Fig. 2). Secondary fish species included pouts (7 \% by mass), sea bass, Dicentrarchus labrax (6 \% by mass), sea bream, Spondyliosoma cantharus (4 \% by mass) and sardine (3\% by mass). Finally, blue whiting and sprat, Sprattus sprattus, represented respectively $13 \%$ and $11 \%$ by number but, owing to their very small body size ( 9 and $12 \mathrm{~cm})$, less than $1 \%$ by mass. Among cephalopods, only Loligo spp. (L. vulgaris and/or L. forbesi) was found, and reached more than $9 \%$ by reconstructed biomass.

\subsubsection{Prey sizes}

Overall prey size distribution ranged from 18 to $667 \mathrm{~mm}$ with the mean at $228 \mathrm{~mm}$ (Fig. 3) and displayed three modes. Prey $<160 \mathrm{~mm}$ and prey from $160-320 \mathrm{~mm}$ accounted for $41 \%$ and $44 \%$ by number respectively, whereas prey $>320670 \mathrm{~mm}$ represented $16 \%$ by number. Prey larger than $160 \mathrm{~mm}$ provided about $96 \%$ by mass of the diet.

\subsection{Comparison of the diet of harbour porpoise and bottlenose dolphin}

Bottlenose dolphin appeared to feed on a more diversified diet (33 species) than the harbour porpoise (18 species). But, more than $70 \%$ of the harbour porpoise prey (13 species) were found in the diet of the bottlenose dolphin. Similarly, dietary diversity was higher in bottlenose dolphin than in harbour porpoise $\left(\mathrm{H}^{\prime}{ }_{\text {Tursiops }}=3.58,95 \% \mathrm{CI}\right.$ : 3.31-3.58, compared to $\mathrm{H}_{\text {Phocaena }}=2.83,95 \% \mathrm{CI}$ : 2.76-2.98). Again, equitability was also higher in the bottlenose dolphin than in the harbour porpoise ( $\mathrm{E}_{\text {Tursiops }}=0.72,95 \% \mathrm{CI}$ : $0.70-0.75$, compared to $\mathrm{E}_{\text {Phocaena }}=0.63$, 95\%CI: 0.64-0.69). The niche overlap calculated with the Pianka index was of 0.45 by relative abundance and only 0.25 by mass.

Statistical testing of dietary differences gave equivocal conclusions. On a general point of view, the Mantel test indicated that the diets of harbour porpoise and bottlenose dolphin differed significantly in prey composition $(\mathrm{P}<0.05)$ and prey length distributions as well $(\mathrm{P}<0.001)$ (Fig. 3). However, on a more specific points of view, the projection of stomach contents in the CAs (Fig. 4) showed some samples were very close in their prey species composition between the two predators. Similarly, there was important overlaps in length distributions for many shared prey species (Table 3) such as scads, mackerel, anchovy or sandsmelt; moreover, length distributions for sardine were statistically identical $(\mathrm{P}<0.001)$ in both predators.

\section{Discussion}

\subsection{General}

The present work is the first quantitative study of the diet of the harbour porpoise and the bottlenose dolphin in the Bay of Biscay, two of the main top-predators of coastal and shelf habitats in the area. Several limitations are inherent to a small sample of stomach contents from stranding schemes. Thus, for a comparison of the diet of two predators, the results could be affect by the pooling of the data across time and space. However, in this study, the two samples were comparable because distributed across all sex and age classes (sex identified at necropsy, age identified from teeth sections; ULR/CRMM unpublished data), the repartition of stranding were similar for the two cetaceans across years and seasons and mostly came from the same large area, the Bay of Biscay and the western channel. Secondly, a characteristics of stranded materials, compared to material obtained from freshly by-caught animals is that the stomach content is often reported to be merely made up of digested material (Pierce and Boyle, 1991). However, in this work, the mass of food material collected represented $22 \%$ and $16 \%$ of the reconstructed mass for harbour porpoise and bottlenose dolphin respectively, a ratio not very different from figures obtained in bycaught dolphins (24\% in common dolphin, $21 \%$ in striped dolphin, Ringelstein et al., in press; Pusineri et al., in press). Nonetheless, this is likely to cause some biases in the quantification of the importance by number and by mass of the different species as the various diagnostic parts used in the analyses do not have the same retention times in the stomachs (e.g. Murie, 1987; Pierce and Boyle, 1991; Santos et al., 2001b). 
This effect is evidenced, principally for bottlenose dolphins, since remains of large species found were mostly accumulated material. Consequently, the contribution of this kind of prey, here hake, mullets or squids, may be overestimated. Given these limitations shared by both species in this study, the present work nonetheless provides new quantitative figures on the dietary composition of these two top predators on the continental shelf of Bay of Biscay and adjacent areas and allows assessment of dietary overlap.

The diet of the harbour porpoise was mostly composed of fish $(98 \% \mathrm{M})$. The assemblage of species revealed the prevalence of small schooling fish living close to the seafloor. The ingested biomass was essentially made up of four species accounting for an approximately equal share of the diet: scads, sardine, blue whiting and whiting. A striking aspect of this study was the presence of some offshore prey species such as northern krill, pearlsides (Maurolicus muelleri) and, to a lesser extent, blue whiting, suggesting that the harbour porpoise is not strictly limited to coastal waters. The diet of the bottlenose dolphin was characterised by the presence of large specimens of demersal fish and cephalopods. Fish made up a total of $91 \% \mathrm{M}$. Hake was the central prey with $41 \% \mathrm{M}$, complemented by mullets, scads, pouts, sea bass and Loligo squids.

The comparison of the two diets suggests that these predators essentially share the same prey profile, with demersal prey being the most important complemented by some pelagic species. Several prey species are common in the two diets and even the length distributions of some of them, such as sardine or scads, are very similar. However, global indices such as the Mantel test or the Pianka's index indicate no or weak overlap. A fair amount of segregation is also obtained in terms of prey size ranges, as bottlenose dolphin preys on larger specimens $(c .200-600 \mathrm{~mm})$ than harbour porpoise does $(c .100-300 \mathrm{~mm})$.Seemingly, the former tends to forage further offshore, in deeper waters as shown by the abundance of hake and particularly of large specimens on the outer shelf (Poulard, 2001) and the stomach contents as well (this work). On this latter point however, overlap between the two species also exists as shown by the presence in the food of the harbour porpoise of blue whiting, pearlsides and northern krill, three species that are more likely to be found close to the slope than along the coast (Mauchline, 1960; Quéro et al., 2003).

\subsection{Comparisons with previous studies}

The diets of these small cetaceans have been studied in many regions. The diet of the harbour porpoise is generally composed of gadids and clupeids, complemented by sandeels and gobies, but at prey species level its composition varies between areas (e.g. Börjesson et al., 2003; Rae, 1965; Santos et al., 2004; Smith and Gaskin, 1974, present work). Thus, the harbour porpoise can be considered as a predator of small demersal prey (although clupeids are pelagic fish, they often dwell near the seafloor). The diet of the bottlenose dolphin varies a lot between study areas, possibly as a result of local prey availability combined with highly flexible foraging tactics. Pelagic and demersal fish, cephalopods and even crustaceans can be locally predominant in the diet (e.g. Cockcroft and Ross, 1990; Barros et al., 2000; Santos et al, 2001a); however, the bottlenose dolphin is also often described as a strictly demersal feeder (Gunter, 1942; Tomilin, 1957; Evans, 1980; Barros and Odell, 1990; Blanco et al., 2001; present work). In terms of foraging tactics, the bottlenose dolphin is extremely flexible among delphinids as it was shown to develop original feeding techniques such as crater-feeding (Rossbach and Herzing, 1997) or inducing fish schools to strand on mud banks (Lewis and Schroeder, 2003).

The compositions of the food of both the harbour porpoises and bottlenose dolphins in the Bay of Biscay largely differ from the diet of the common dolphin, Delphinus delphis, the other abundant small cetacean in the area. This latter, known to be a cooperative pelagic feeder, locally displays a diet almost exclusively composed of small schooling pelagic fish, such as anchovy, sardine, scads and mackerel (CRMM/ULR, unpublished data).

\subsection{Ecological significance}

The dietary results suggest that the two predators show partial dietary overlap over several major dimensions of the foraging niche: prey profile, foraging habitats, prey species and size range. Is this amount of overlap sufficient to generate interference competition?

In marine ecosystems, resource is patchily distributed; this is often reported for schooling forage species like scads or clupeids but it is also the case for most demersal species. The optimal foraging theory MacArthur and Pianka, 1966) suggests that top marine predators would have to go from patch to patch in order to maximize the ratio between foraging benefits and costs. If interference competition is hardly conceivable when one considers bottlenose dolphins and harbour porpoise living sympatrically at the scale of the whole Bay of Biscay and western Channel, such behaviour is more plausible when one considers the scale of a prey school that would be exploited jointly by groups of the two predators. Consequently, even if only one prey is shared by two predators, interspecific interaction can occur. The risk of such competition 
would be a function of the size of the prey aggregation, the number of predators present in the same patch and the duration of the mixed-predators association. For example, no interference competition was observed in the Azores in mixed-species feeding aggregation of dolphins, large tunas and seabirds (Clua and Grosvalet, 2001). In this case, prey constitute large patches and predation results in and relies on the formation of a compact and transient "ball" of several thousands of fish close to the surface; in that case the mixed-predators aggregations were of short duration (5 to 20 minutes). However, other conditions seem to be more propitious to aggressive interactions. For instance, between spotted dolphins, Stenella frontalis, and bottlenose dolphins in the Bahamas, aggressions on spotted dolphins by bottlenose dolphins were recorded in situations of mixed-species foraging that lasted up to more than a day and targeted bottom resources (Herzing and Johnson, 1997; Herzing et al., 2003). Moreover, interference competition would be more likely to induce aggressive interactions in case of marked asymmetries between the two predators involved (differences in body size, strength or group size) (Maynard Smith, 1982). In the present study case, the bottlenose dolphin is clearly larger and stronger than the harbour porpoise and it generally forages in larger groups than the harbour porpoise does.

These elements suggest that all circumstances are gathered to facilitate aggressive behaviors on harbour porpoises by bottlenose dolphins when they forage together on the same prey patch. This hypothesis is strengthened by dietary results from Scotland, an area well known for the frequency of aggressive interactions between harbour porpoises and bottlenose dolphins. A recent study showed that sandeels are more abundant in the stomach contents of porpoises killed by Tursiops compared to other causes of death (Santos et al., 2004) and in this area, sandeels are also the second more abundant prey in the diet of bottlenose dolphins (Santos et al., 2001b).

If this interference competition is frequent enough, it could cause some shift in habitat or resource use in the weaker species. An illustration of such an effect could be the higher proportion of small prey items in the diet of the harbour porpoise, according to the principle stated by Milinski (1982) for the less successful competitor. In some cases, high rates of competition killing are sufficient to limit population size of the killed species (Laurenson, 1995). In the North Sea, harbour porpoises largely outnumber bottlenose dolphins (Hammond et al., 2002), consequently, attacks by bottlenose dolphin should only have a limited impact on harbour porpoise population. By contrast in the Bay of Biscay, where the ratio between the two species is well in favour of the larger more successful species, these interactions may be an additional pressure that contribute to limit harbour porpoise populations in the area.

\section{Acknowledgements}

This work was part of a larger research programme on the role and the dietary preferences of small cetaceans and other pelagic top predators in the Bay of Biscay and adjacent Atlantic areas. Funding was provided by the EU project BIOCET and the national project Chantier Golfe de Gascogne, Programme National d'Environnement Côtier. The CRMM, Centre de Recherche sur les Mammifères Marins, is funded by Ministère de l'Ecologie et du Développement Durable and by Communauté d'Agglomération de la Ville de La Rochelle. We are particularly grateful to members of the French Stranding Scheme and the whole staff of CRMM for providing the samples; the map was made by O. Van Canneyt (CRMM) and bootstrap simulations were carried out with help from G. Certain (University of La Rochelle and CNRS). The identification of prey reference specimens was checked by J.-P. Lagardère (CREMA, L'Houmeau, France), J.-C. Quéro (Muséum d'Histoire Naturelle, La Rochelle, France) and B. Santos Vasquez (University of Aberdeen, Aberdeen, UK). They have all offered their time and competence and are gratefully acknowledged for their help.

\section{LITERATURED CITED}

Baird, R.W., 1998. An interaction between Pacific white-sided dolphins and a neonatal harbor porpoise. Mammalia 62, 129-134.

Barros, N.B., Odell, D.K., 1990. Food habits of bottlenose dolphins in the southeastern United States. In: Leatherwood, S., Reeves, R.R. (Eds.), The bottlenose dolphin. Academic Press, London, pp.309-328.

Barros, N., Parsons, E.C.M., Jefferson, T.A., 2000. Prey of offshore bottlenose dolphins from the South China Sea. Aquatatic Mammals 26, 2-6.

Blanco, C., Salomon, O., Raga, J.A., 2001. Diet of the bottlenose dolphin (Tursiops truncatus) in the western Mediterranean Sea. Journal of Marine Biological Association of the United Kingdom 81, 10531058.

Börjesson, P., Berggren, P., Ganning, B., 2003. Diet of harbour porpoises in the Kattegat and Skagerrak seas: Accounting for individual variation and sample size. Marine Mammal Science 19, 38-58. 
Caro, T.M., Stoner, C.J., 2003. The potential for intraspecific competition among African carnivores. Biological Conservation 110, 67-75.

Clarke, M.R., 1986. A handbook for the identification of cephalopod beaks. Clarendon Press, Oxford, 274p.

Clua, E., Grosvalet, F., 2001. Mixed-species feeding aggregation of dolphins, large tunas and seabirds in the Azores. Aquating Living Resources 14, 11-18.

Cockcroft, V.G., Ross, G.J.B., 1990. Food and feeding of the India Ocean bottlenose dolphin off southern Natal, South Africa. In: Leatherwood, S., Reeves, R.R. (Eds.), The bottlenose dolphin, Academic Press, London, pp.295-308.

Croxall, J.P., 1993. Diet. In: Laws, R.M. (Ed.), Antarctic Seals, Cambridge, University Press Cambridge, pp.268-290.

Evans, P.G.H., 1980. Cetaceans in British waters. Mammal Review 10, 267-276.

Gunter, G., 1942. Contributions to the natural history of the bottlenose dolphin, Tursiops truncatus (Montague), on the Texas coast, with particular reference to food habits. Journal of Mammalogy 23, 267276.

Hammond, P.S., Berggren, P., Benke, H., Borchers, D.L., Collet, A., Heide-Jørgensen, M.P., Heimlich, S., Hiby, A.R., Leopold, M., Øien, N., 2002. Abundance of harbour porpoise and other cetaceans in the North Sea and adjacent waters. Journal of Applied Ecology 39, 361-376.

Härkönen, T.J., 1986. Guide to the otoliths of the bony fishes of the northeast Atlantic. Danbiu ApS, Hellerup, 256p.

Herzing, D.L., Johnson, C.M., 1997. Interspecific interactions between Atlantic spotted dolphins (Stenella frontalis), and bottlenose dolphins (Tursiops truncatus) in the Bahamas. Aquatic Mammals 23, 85-100.

Herzing, D.L., Moewe, K., Brunnick, G.J., 2003. Interspecies interactions between Atlantic spotted dolphins, Stenella frontalis, and bottlenose dolphins, Tursiops truncatus, on Great Bahama Bank, Bahamas. Aquatic Mammals 29, 335-341.

Ihaka, R., Gentleman, R., 1996. R: a language for data analysis and graphics. Journal of Computational and Graphical Statistics 5, 299-314.

Jefferson, T.A., Stacey, P.J., Baird, R.W., 1991. A review of killer whale interactions with other marine mammals: predation to co-existence. Mammal Review 21, 151-180.

Jepson, P.D., Baker, J.R., 1998. Bottlenose dolphins (Tursiops truncatus) as a possible cause of acute traumatic injuries in porpoises (Phocoena phocoena). Veterinary Record 143, 614-615.

Lagardère, J.-P., 1971. Les crevettes des côtes du Maroc. Travaux de l'Institut Scientifique Chérifien et de la Faculté des Sciences, Série Zoologique N³6, 140p.

Laurenson, M.K., 1995. Implications of high offspring mortality for cheetah population dynamics. In: Sinclair, A.R.E., Arcese, P. (Eds.) Serengeti II: Dynamics, management and conservation of an ecosystem, University of Chicago Press, Chicago, pp.385-399.

Lewis, J.S., Schroeder, W.W., 2003. Mud plume feeding, a unique foraging behaviour of the bottlenose dolphin in the Florida Keys. Gulf of Mexico Science 21, 92-97.

Mauchline, J., 1960. The biology of euphausiid crustacean Meganyctiphanes norvegica. Proceedings of the Royal Society of Edinburgh B 67, 141-179.

MacArthur, R.H., Pianka, E.R., 1966. On the optimal use of a patchy environment. American Naturalist 100, 603-609.

Maynard Smith, J., 1982. Evolution and the theory of games. Cambridge University Press, Cambridge, 226p.

Milinski, M., 1982. Optimal foraging: the influence of intraspecific competition on diet selection. Behavioral Ecology and Sociobiology 11, 109-115.

Murie, D.J., 1987. Experimental approaches to stomach content analyses of piscivorus marine mammals. In: Huntley, A.C., Costa, D.P., Worthy, G.A.J., Castellini, M.A. (Eds.), Approaches to Marine Mammal Energetics, Special Publication $n^{\circ} 1$, The Society for Marine Mammalogy, Lawrence, pp.147-163.

Orr, J.R., Harwood, L.A., 1998. Possible aggressive behavior between a narwhal (Monodon monoceros) and a beluga (Delphinapterus leucas). Marine Mammal Science 14, 182-185.

Palamores, F., Caro, T.M., 1999. Interspecific killing among mammalian carnivores. American Naturalist 153, 492-508.

Patterson, G.B., 1986. A statistical method of testing for dietary differences. New Zealand Journal of Zoology 13, 113-115.

Patterson, I.A., Reid, R.J., Wilson, B., Grellier, K., Ross, H.M., Thompson, P.M., 1998. Evidence for infanticide in bottlenose dolphins: an explanation for violent interactions with harbour porpoises. Proceedings of the Royal Society of London B 265, 1167-1170.

Pierce, G.J., Boyle, P.R., 1991. A review of methods for diet analysis in piscivorous marine mammals. Oceanography and Marine Biology Annual Review 29, 409-486. 
Poulard, J.-C., 2001. Distribution of hake (Merluccius merluccius, Linnaeus, 1758) in the Bay of Biscay and the Celtic sea from the analysis of French commercial data. Fisheries Research 50, 173-187.

Psarakos, S., Herzing, D.L., Marten, K., 2003. Mixed-species associations between Pantropical spotted dolphins (Stenella attenuata) and Hawaiian spinner dolphins (Stenella longirostris) off Oahu, Hawaii. Aquatic Mammals 29, 390-395.

Pusineri, C., Magnin, V., Meynier, L., Spitz, J., Hassani, S., Ridoux, V., in press. Food and feeding ecology of the common dolphin (Delphinus delphis) in the oceanic northeast Atlantic and comparison with its diet in neritic areas. Marine Mammal Science.

Quéro, J.-C., Porché, P., Vayne, J.-J., 2003. Guide des poissons de l'Atlantique européen, Delachaux et Niestlé, Les Guides du Naturaliste, Lonay / Paris, 465p.

Rae, B.B., 1965. The food of the common porpoise (Phocoena phocoena). Journal of Zoology 146, 114122.

Ringelstein, J., Pusineri, C., Hassani, S., Meynier, L., Nicolas, R., Ridoux, V., in press. The food and feeding ecology of the striped dolphin, Stenella coeruleoalba, in the oceanic Northeast Atlantic. Journal of Marine Biological Association of the United Kingdom.

Rossbach, K.A., Herzing, D.L., 1997. Underwater observations of benthic-feeding bottlenose dolphins (Tursiops truncatus) near Grand Bahama Island, Bahamas. Marine Mammal Science 13, 498-504.

Reynolds, J.C., Aebischer, N.J., 1991. Comparison and quantification of carnivore diet by faecal analysis: a critique, with recommendations, based on a study of the Fox Vulpes vulpes. Mammal review 21, 97-122.

Ridoux, V., 1994. The diets and dietary segregation of seabirds at the subantarctic Crozet Islands. Marine Ornithology 22, 1-192.

Ross, H.M., Wilson, B. 1996. Violent interactions between bottlenose dolphins and harbour porpoises. Proceedings of the Royal Society of London B 263, 283-286.

Santos, M.B., Clarke, M.R., Pierce, G.J., 2001a. Assessing the importance of cephalopods in the diets of marine mammals and other top predators: problems and solutions. Fisheries Research 52, 121-139.

Santos, M.B., Pierce, G.J., Reid, R.J., Patterson, I.A.P., Ross, H.M., Mente, E., 2001b. Stomach contents of bottlenose dolphins (Tursiops truncatus) in Scottish waters. Journal of Marine Biological Association of the United Kingdom 81, 873-878.

Santos, M.B., Pierce, G.J., Learmonth, J.A., Reid, R.J., Ross, H.M., Patterson, I.A.P., Reid, D.G., Beare, D., 2004. Variability in the diet of harbour porpoises (Phocoena phocoena) in Scottish waters 1992-2003. Marine Mammal Science 20, 1-27.

Sih, A., 1993. Effects of ecological interactions on forager diets: competition, predation risk, parasitism and prey behaviour. In: Hughes, R.N. (Ed.), Diet selection: An interdisciplinary approach to foraging behaviour, Blackwell scientific publications, Oxford, pp.182-211.

Smith, G.J.D., Gaskin, D.E., 1974. The diet of harbour porpoises (Phocoena phocoena (L.)) in coastal waters of Eastern Canada, with special reference to the Bay of Fundy. Canadian Journal of Zoology 52, 777-782.

Tomilin, A.G., 1957. Mammals of the USSR and adjacent countries, Vol. IX, Cetacea. Israel Program for scientific translations, Jerusalem 756p. 
Table 1: Prey found in stomach contents of Phocoena phocoena stranded on the Northeast Atlantic French coast

Table 2: Prey found in stomach contents of Tursiops truncatus stranded on the Northeast Atlantic French coast

Table 3: Common species in the diets of harbour porpoise and of bottlenose dolphin 
Table 1: Prey found in stomach contents of Phocoena phocoena stranded on the Northeast Atlantic French coast

\begin{tabular}{|c|c|c|c|c|c|c|c|c|c|c|}
\hline & \multirow{2}{*}{$\begin{array}{c}\text { Occurrence } \\
\% \mathrm{O}\end{array}$} & \multicolumn{2}{|c|}{ Number } & \multicolumn{3}{|c|}{ Body length (mm) } & \multicolumn{2}{|c|}{ Body mass (g) } & \multicolumn{2}{|c|}{ Biomass } \\
\hline & & $\%$ & P75\% & $\mathbf{n}$ & $x \pm \sigma$ & Range & $x \pm \sigma$ & Range & $\%$ & P75\% \\
\hline FISHES & 88.5 & 84.5 & & & & & & & 98.2 & \\
\hline \multicolumn{11}{|l|}{ Engraulidae } \\
\hline Engraulis encrasicolus & 15.4 & 0.5 & $0-1$ & 12 & $116.3 \pm 24.2$ & $81.1-157.7$ & $9.9 \pm 6.4$ & $2.6-23.2$ & 0.3 & $0-1$ \\
\hline \multicolumn{11}{|l|}{ Clupeidae } \\
\hline Sardina pilchardus & 30.8 & 2.3 & $1-7$ & 67 & $199.8 \pm 29.9$ & $116-245.9$ & $128 \pm 21.9$ & $69.8-163.8$ & 21.3 & $11-38$ \\
\hline \multicolumn{11}{|l|}{ Sternoptychidae } \\
\hline Maurolicus muelleri & 3.8 & 0.2 & $0-1$ & 4 & $29.4 \pm 3.1$ & $25-33.7$ & $0.1 \pm 0.2$ & $0-0.4$ & 0.0 & 0 \\
\hline \multicolumn{11}{|l|}{ Merluccidae } \\
\hline Merluccius merluccius & 11.5 & 0.3 & $0-1$ & 12 & $182 \pm 70.7$ & $79.7-258.7$ & $56.1 \pm 39.2$ & $5.2-110.7$ & 1.4 & $0-3$ \\
\hline \multicolumn{11}{|l|}{ Gadidae } \\
\hline Gadiculus argenteus & 7.7 & 0.2 & $0-1$ & 6 & $67.1 \pm 9.4$ & $58-80$ & $2.1 \pm 1.3$ & $0.9-4$ & 0.0 & 0 \\
\hline Trisopterus spp & 34.6 & 28.7 & $3-36$ & 57 & $54.3 \pm 14$ & $15.7-156.7$ & $1.9 \pm 2.9$ & $0-36.3$ & 3.9 & $1-9$ \\
\hline Merlangius merlangus & 15.4 & 2.5 & $0-8$ & 38 & $233.4 \pm 40.8$ & $117.4-291.1$ & $111.2 \pm 51.2$ & $12.3-209.1$ & 20.3 & $11-41$ \\
\hline Micromesistius poutassou & 38.5 & 18.5 & $14-27$ & 154 & $121.3 \pm 38.3$ & $109.8-290.1$ & $16.1 \pm 13.6$ & $9.1-119.7$ & 21.3 & $5-22$ \\
\hline \multicolumn{11}{|l|}{ Carangidae } \\
\hline Trachurus trachurus & 26.9 & 5.2 & $2-16$ & 152 & $187 \pm 56$ & $70.3-276.9$ & $73.8 \pm 52.2$ & $4.2-190.5$ & 27.6 & $18-45$ \\
\hline \multicolumn{11}{|l|}{ Scombridae } \\
\hline Scomber scombrus & 3.8 & 0.1 & $0-1$ & 2 & $305.4 \pm 1.3$ & $304.1-306.7$ & $214.8 \pm 2.7$ & $212.1-217.5$ & 0.9 & $0-2$ \\
\hline \multicolumn{11}{|l|}{ Gobiidae } \\
\hline Undeterminated gobiidae & 23.1 & 21.5 & $12-33$ & 117 & $44 \pm 10.8$ & $22.4-86.7$ & $0.7 \pm 0.7$ & $0.1-6.6$ & 1.1 & $0-2$ \\
\hline \multicolumn{11}{|l|}{ Atherinidae } \\
\hline Atherina presbyter & 7.7 & 0.3 & $0-1$ & 6 & $86.3 \pm 15.9$ & $68.7-114.1$ & $4.66 \pm 2.9$ & $2.1-9.9$ & 0.1 & $0-1$ \\
\hline \multicolumn{11}{|l|}{ Others Fish } \\
\hline Undeterminated fishes & 23.1 & 4.1 & $0-12$ & - & - & - & - & - & - & - \\
\hline
\end{tabular}




\begin{tabular}{|c|c|c|c|c|c|c|c|c|c|c|}
\hline CEPHALOPODS & 46.2 & 2.8 & & & & & & & 1.6 & \\
\hline \multicolumn{11}{|l|}{ Loliginidae } \\
\hline Loligo spp & 11.5 & 0.2 & $0-1$ & 3 & $39.2 \pm 22.1$ & $8.3-58.9$ & $9 \pm 5.2$ & $1.9-14.2$ & 0.1 & $0-1$ \\
\hline Alloteuthis spp & 19.2 & 0.6 & $0-1$ & 5 & $96.7 \pm 25.9$ & $62.5-128.6$ & $11.1 \pm 5.8$ & $5.5-28$ & 0.5 & $0-1$ \\
\hline \multicolumn{11}{|l|}{ Sepiolidae } \\
\hline Underteminated Sepiolidae & 23.1 & 1.7 & $1-5$ & 6 & $15.8 \pm 0.2$ & $15.6-16.1$ & $1.5 \pm 0.1$ & $5.6-6$ & 0.2 & $0-1$ \\
\hline \multicolumn{11}{|l|}{ Ommastrephidae } \\
\hline Underteminated ommastrephidae & 3.8 & 0.1 & $0-1$ & 2 & $77 \pm 5.3$ & $66.8-77.3$ & $27.5 \pm 5.5$ & $22-33$ & 0.2 & $0-1$ \\
\hline \multicolumn{11}{|l|}{ Octopotidae } \\
\hline Underteminated Octopotidae & 3.8 & 0.1 & $0-1$ & 2 & $56.5 \pm 21.3$ & $35.3-77.8$ & $55 \pm 46$ & $9-100.9$ & 0.7 & $0-3$ \\
\hline \multicolumn{11}{|l|}{ Others Cephalopods } \\
\hline Undetermined Cephalopods & 7.6 & 0.2 & $0-1$ & - & - & - & - & - & - & - \\
\hline CRUSTACEANS & 11.5 & 12.7 & & & & & & & 0.2 & \\
\hline \multicolumn{11}{|l|}{ Euphausiacea } \\
\hline Meganyctiphanes norvegica & 11.5 & 12.7 & $0-16$ & 45 & $28.6 \pm 0.2$ & $27.6-29$ & $0.2 \pm 0.1$ & $0.01-0.6$ & 0.2 & $0-1$ \\
\hline
\end{tabular}

$\mathrm{N}$, number of each prey ; P75\%, 75\% percentile ; n, number of measurement ; M, total mass of each prey in gram ; $x$, mean value ; $\sigma$, standard deviation 
Table 2: Prey found in stomach contents of Tursiops truncatus stranded on the Northeast Atlantic French coast

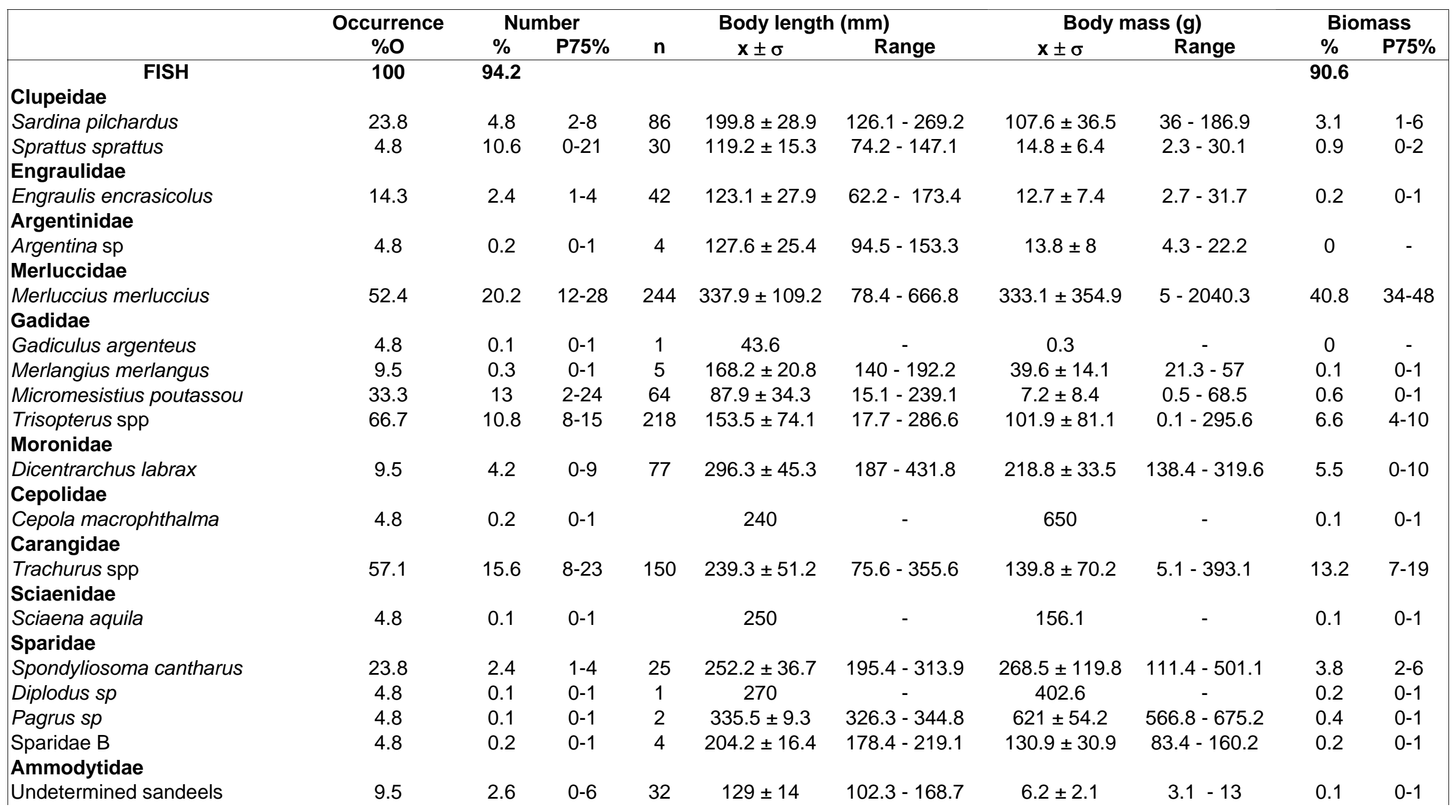




\begin{tabular}{|c|c|c|c|c|c|c|c|c|c|c|}
\hline $\begin{array}{l}\text { Scombridae } \\
\text { Scomber scombrus } \\
\text { Gobidae }\end{array}$ & 9.5 & 0.9 & $0-2$ & 8 & $374.8 \pm 26.8$ & $333.1-417.5$ & $396.5 \pm 83.3$ & $276.1-538.9$ & 2.3 & $1-4$ \\
\hline $\begin{array}{l}\text { Undetermined gobids } \\
\text { Mugilidae }\end{array}$ & 9.5 & 0.3 & $0-1$ & 6 & $86.9 \pm 16.4$ & $67.9-109.7$ & $8.1 \pm 5.8$ & $2.6-16.6$ & 0 & - \\
\hline $\begin{array}{l}\text { Undetermined mullets } \\
\text { Atherinidae }\end{array}$ & 19 & 4.5 & $1-8$ & 32 & $314.5 \pm 99.3$ & $221.7-543.3$ & $411.8 \pm 515.5$ & $92.4-1942.8$ & 12.1 & $6-18$ \\
\hline $\begin{array}{l}\text { Atherina presbyter } \\
\text { Soleidae }\end{array}$ & 4.8 & 0.1 & $0-1$ & 1 & 73.1 & - & 2.5 & - & 0 & - \\
\hline $\begin{array}{l}\text { Undetermined soleids } \\
\text { Others fish }\end{array}$ & 4.8 & 0.2 & $0-1$ & 2 & $294 \pm 6.5$ & $287.6-300.5$ & $249.9 \pm 18.2$ & 231.7 - 268 & 0.3 & $0-1$ \\
\hline Others flatfish & 14.3 & 0.3 & $0-1$ & 5 & $239.2 \pm 48$ & $184.6-307.2$ & $107.4 \pm 76.4$ & $34-225.4$ & 0.2 & $0-1$ \\
\hline $\begin{array}{l}\text { Unknow A } \\
\text { Undetermined fish }\end{array}$ & $\begin{array}{l}4.8 \\
4.8\end{array}$ & $\begin{array}{l}0.2 \\
0.2\end{array}$ & $\begin{array}{l}0-1 \\
0-1\end{array}$ & & - & - & - & - & - & \\
\hline $\begin{array}{l}\text { CEPHALOPODS } \\
\text { Loliginidae }\end{array}$ & 42.9 & 2.8 & & & & & & & 9.4 & \\
\hline Alloteuthis spp & 9.5 & 1.1 & $0-2$ & 11 & $63.6 \pm 10.6$ & $46.6-83$ & $4.6 \pm 1.5$ & $2.6-7.4$ & 0 & \\
\hline $\begin{array}{l}\text { Loligo spp } \\
\text { Sepiidae }\end{array}$ & 38.1 & 2.5 & $2-4$ & 23 & $235.5 \pm 119.8$ & $42-466$ & $603.3 \pm 562.4$ & $2.2-1614.7$ & 9.3 & 3-15 \\
\hline $\begin{array}{l}\text { Sepia sp } \\
\text { CRUSTACEANS } \\
\text { Crangonidae }\end{array}$ & $\begin{array}{l}4.8 \\
19\end{array}$ & $\begin{array}{c}0.1 \\
2\end{array}$ & $0-1$ & 1 & 36.2 & - & 1.2 & - & $\begin{array}{l}0 \\
0\end{array}$ & - \\
\hline $\begin{array}{l}\text { Crangon crangon } \\
\text { Pasiphaeidae }\end{array}$ & 4.8 & 1.5 & $0-4$ & & 40 & & 24 & - & 0 & - \\
\hline $\begin{array}{l}\text { Pasiphaea multidentata } \\
\text { Undetermined shrimp }\end{array}$ & $\begin{array}{c}4.8 \\
14.3 \\
\end{array}$ & $\begin{array}{l}0.2 \\
0.4\end{array}$ & $\begin{array}{l}0-1 \\
0-1\end{array}$ & & $\begin{array}{c}100 \\
-\end{array}$ & & 8 & - & 0 & - \\
\hline
\end{tabular}

$\mathrm{N}$, number of each prey ; P75\%, 75\% percentile ; n, number of measurement ; $\mathrm{M}$, total mass of each prey in gram ; $\mathrm{x}$, mean value ; $\sigma$, standard deviation 
Table 3: Common species in the diets of harbour porpoise and of bottlenose dolphin

\begin{tabular}{|lrrrrrr|}
\hline \multicolumn{1}{|c}{ SPECIES } & \% $_{\mathbf{P p}}$ & $\mathbf{\%}_{\mathbf{T t}}$ & \% $_{\mathbf{P p}_{\mathbf{p p}}}$ & $\mathbf{\%}_{\mathbf{T t}}$ & $\mathbf{L 7 5 \%}_{\mathbf{P p}}$ & $\mathbf{L 7 5 \%}_{\mathbf{T t}}$ \\
\hline Trachurus trachurus & 5.2 & 15.6 & 27.6 & 13.2 & $110-270$ & $180-290$ \\
Sardina pilchardus & 2.3 & 4.8 & 21.3 & 3.1 & $160-240$ & $160-240$ \\
Trisopterus spp & 28.7 & 10.8 & 3.9 & 6.6 & $40-70$ & $50-250$ \\
Micromesistius poutassou & 18.5 & 13.0 & 21.3 & 0.6 & $130-170$ & $50-120$ \\
Merlangius merlangus & 2.5 & 0.3 & 20.3 & 0.1 & $180-280$ & $150-190$ \\
Merluccius merluccius & 0.3 & 20.2 & 1.4 & 40.8 & $80-250$ & $190-430$ \\
Gobiidae & 21.5 & 0.3 & 1.1 & 0.0 & $30-60$ & $70-110$ \\
Scomber scombrus & 0.1 & 0.9 & 0.9 & 2.3 & $300-310$ & $340-400$ \\
Engraulis encrasicolus & 0.5 & 2.4 & 0.3 & 0.2 & $90-150$ & $90-160$ \\
Atherina presbyter & 0.3 & 0.1 & 0.1 & 0.0 & $70-90$ & $70-80$ \\
Gadiculus argenteus & 0.2 & 0.1 & 0.0 & 0.0 & $60-80$ & $40-50$ \\
Loligo spp & 0.2 & 2.5 & 0.1 & 9.3 & $50-60$ & $110-270$ \\
Alloteuthis spp & 0.6 & 1.1 & 0.5 & 0.0 & $70-100$ & $50-80$ \\
\hline
\end{tabular}

\%N, percentage of number ; \%M, percentage of mass ; L75\%, length range including 75\% of prey species ; Pp, Phocoena phocoena ; Tt, Tursiops truncatus 
Fig. 1: Locations of harbour porpoises (dark triangles) and bottlenose dolphins (grey circles) strandings

Fig. 2: Size distributions of main preys in the diets of the harbour porpoise and/or of the bottlenose dolphin in percent number

Fig. 3: Overall prey-size distribution in the diets of the harbour porpoise and of the bottlenose dolphin in percent number and percent mass

Fig. 4 : Plots of the correspondence analysis from the mass of prey per dolphin. The two axis explained $23 \%$ of total inertia 


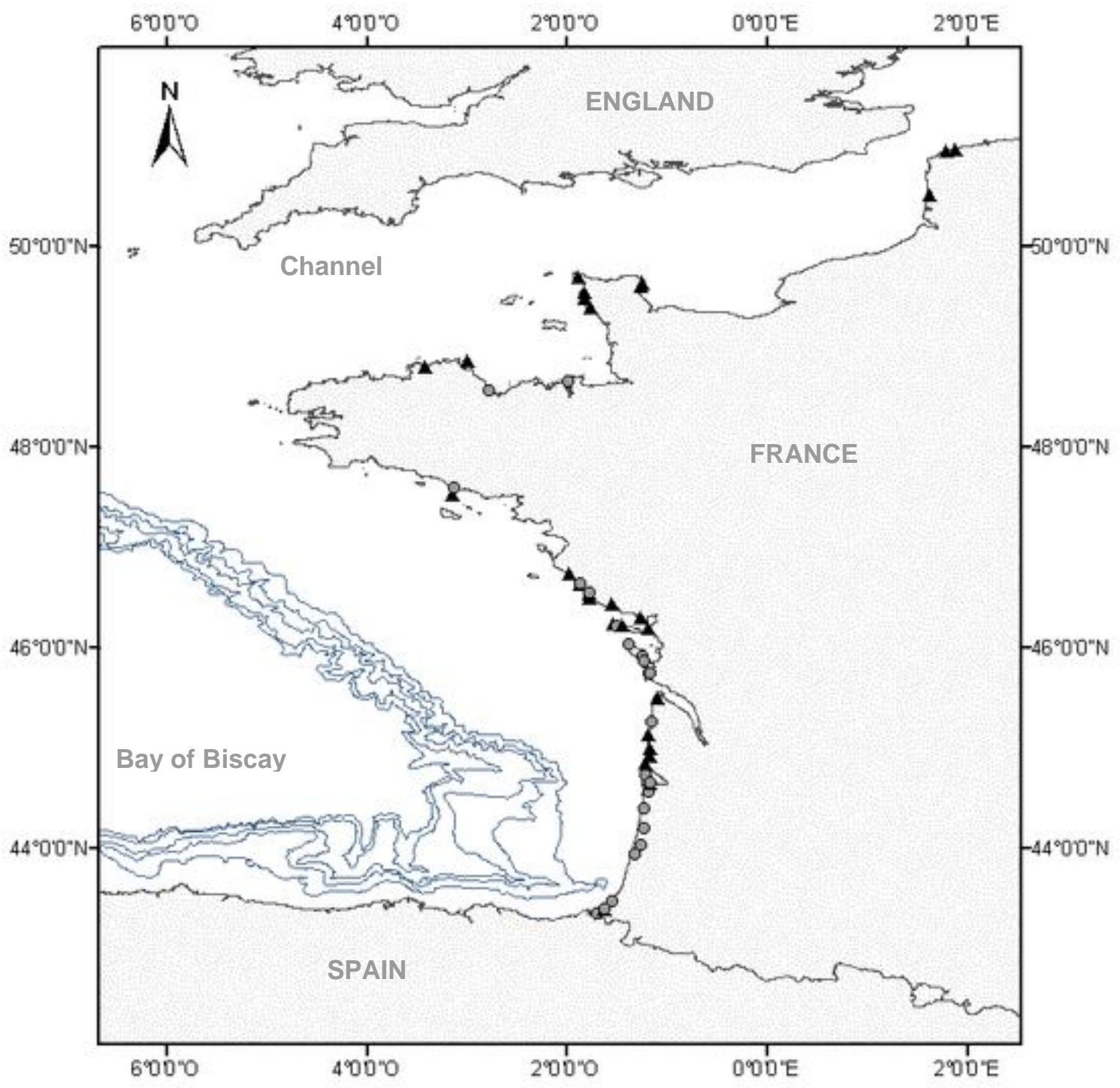

Fig. 1: Locations of harbour porpoises (dark triangle) and bottlenose dolphins (grey circles) strandings 

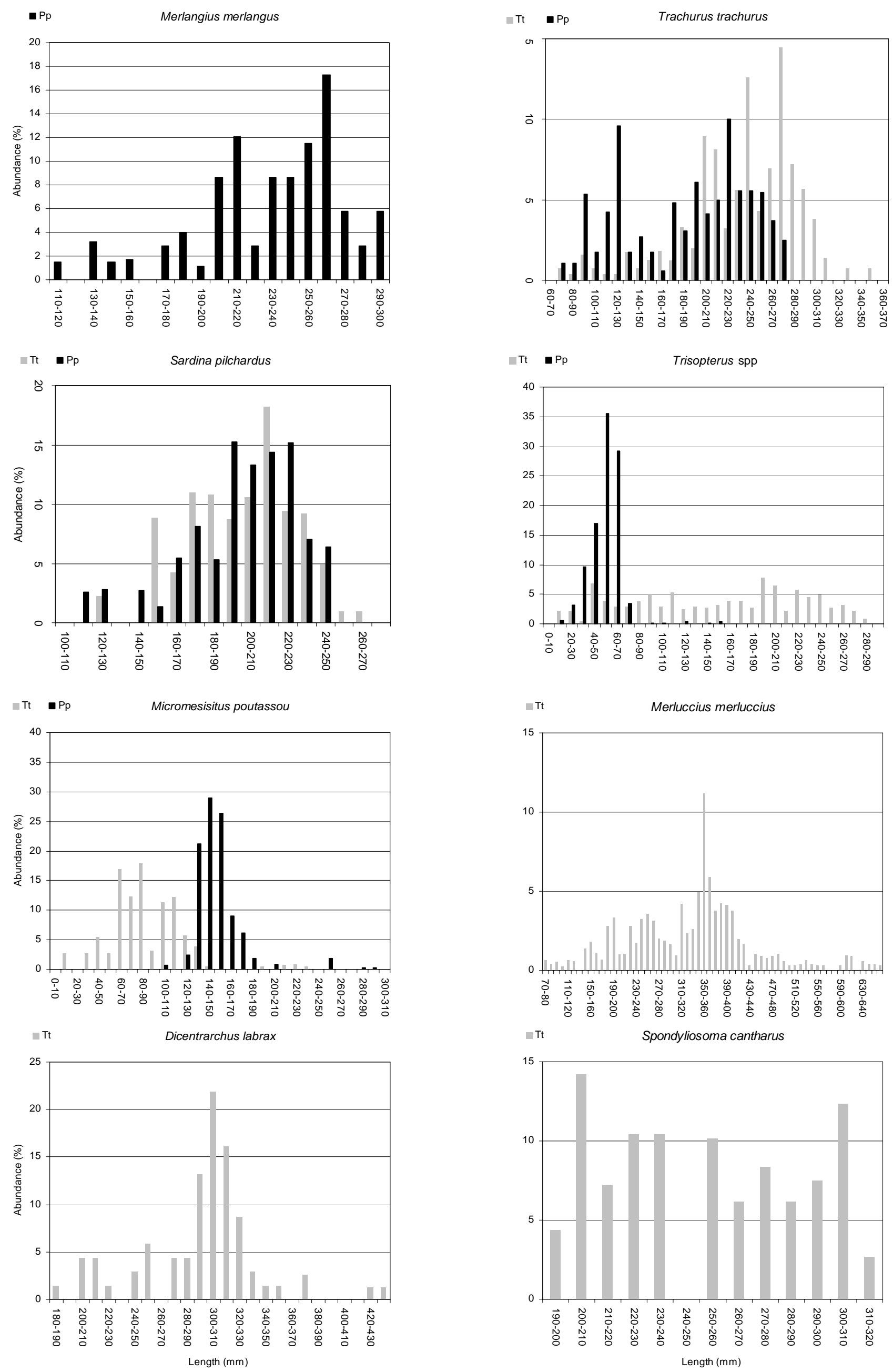

Fig. 2: Size distributions of main preys in the diets of the harbour porpoise and/or of the bottlenose dolphin 


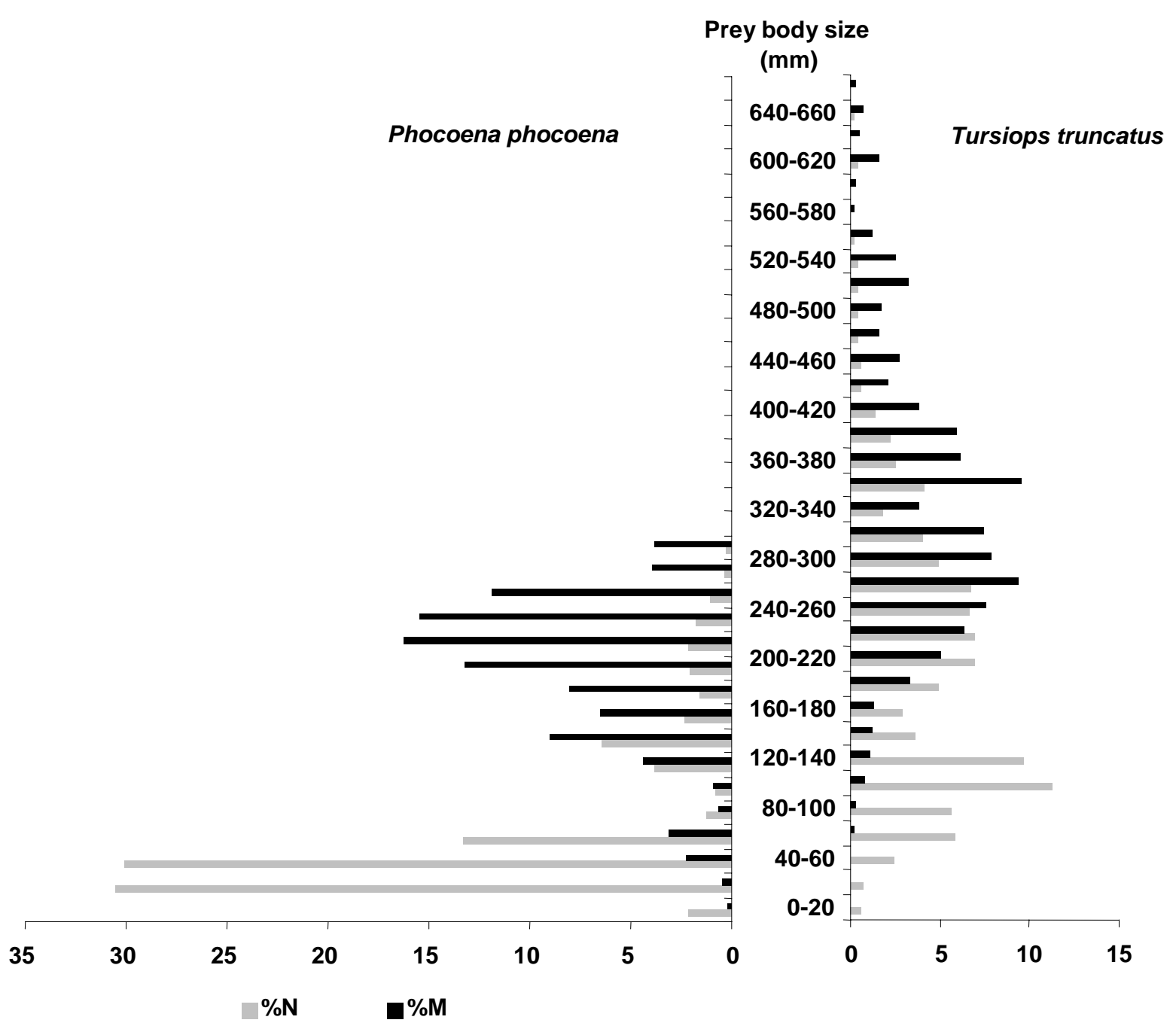

Fig. 3 : Overall prey-size distribution in the diets of the harbour porpoise (left) and the bottlenose dolphin (right) in percent number $(\% \mathrm{~N})$ and percent mass $(\% \mathrm{M})$ 


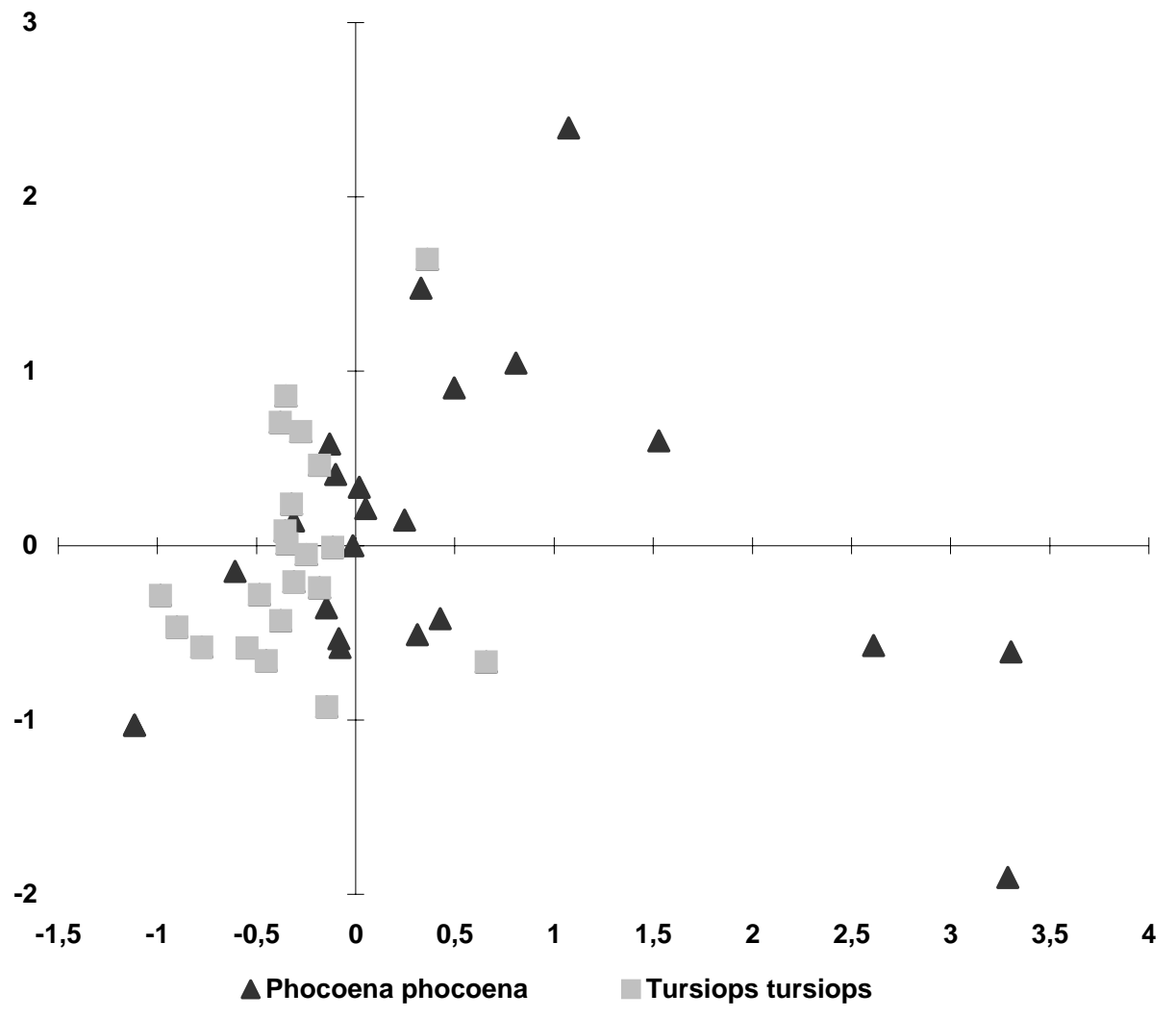

Fig. 4 : Plots of the correspondence analysis from presence or absence for each prey species per cetacean.

The two axis explained $19 \%$ of total inertia 